\title{
Bornéo. La mémoire des grottes, de Luc-Henri Fage et Jean-Michel Chazine
}

Isabelle Leblic

\section{(2) OpenEdition \\ Journals}

Édition électronique

URL : http://journals.openedition.org/jso/6675

DOI : $10.4000 /$ jso. 6675

ISSN : $1760-7256$

Éditeur

Société des océanistes

\section{Édition imprimée}

Date de publication : 30 juin 2012

Pagination : 155

ISBN : 978-2-85430-032-1

ISSN : 0300-953x

\section{Référence électronique}

Isabelle Leblic, "Bornéo. La mémoire des grottes, de Luc-Henri Fage et Jean-Michel Chazine », Journal de la Société des Océanistes [En ligne], 134 | 1er semestre 2012, mis en ligne le 29 juin 2012, consulté le 24 septembre 2020. URL : http://journals.openedition.org/jso/6675; DOI : https://doi.org/10.4000/jso 6675

Ce document a été généré automatiquement le 24 septembre 2020.

(c) Tous droits réservés 


\title{
Bornéo. La mémoire des grottes, de Luc-Henri Fage et Jean-Michel Chazine
}

\author{
Isabelle Leblic
}

\section{RÉFÉRENCE}

FAGE Luc-Henri et Jean-Michel CHAZINE, 2009. Bornéo. La mémoire des grottes, préface de Jean Clottes, Lyon, Fage Éditions, 176 p., bibliogr., chronologie, carte, très nombreuses illustrations couleur.

1 Après une préface de Jean Clottes (pp. 19-20), préhistorien et conservateur général du patrimoine honoraire, évoquant un "patrimoine remarquable, digne des traditions artistiques les plus célèbres» (p. 20) et un prologue des deux auteurs (pp. 21-23) expliquant les origines de l'ouvrage qui «retrace onze expéditions [...] sur l'île de Bornéo, appelée Kalimantan par les Indonésiens » (p. 21), le lecteur entre dans le cœur de l'ouvrage qui comprend quatre parties: "Aventures au pays des Dayak et des Punan» (pp. 25-54), «À la découverte d'un art rupestre unique » (pp.55-82), «Les “Lascaux" de Bornéo » (pp. 83-154) et « Perspectives archéologiques » (pp. 155-171). Le tout est richement illustré par de nombreuses photographies en couleur, des graphiques et des relevés des peintures de l'auteur des trois premières parties, LucHenri Fage, photographe et journaliste, qui effectue des missions spéléologiques au cœur de Bornéo depuis 1988 et a été rejoint en 1992 par l'ethno-archéologue JeanMichel Chazine, auteur de la dernière partie de l'ouvrage.

2 Les deux premiers chapitres («La traversée de Bornéo », pp. 25-35 et «Pionniers de l'archéologie », pp. 36-49) racontent le début de cette découverte, que Luc-Henri Fage fait remonter à son enfance et à sa passion pour les grottes qui l'amena en 1988 à monter une expédition d'inventaire des cavités naturelles qui lui fit traverser intégralement l'île de Bornéo avec une poignée de spéléologues. Puis, il relate cette « 
traversée impossible » pour rendre compte de ses deux premières missions avec JeanMichel Chazine, en 1992 et 1993.

3 Dans la deuxième partie, Luc-Henri Fage continue le récit chronologique de ses découvertes en nous faisant part, de «La découverte imprévue » des mains devenues si célèbres, en 1994, (pp. 54-69), puis en nous emmenant sur « La piste de la préhistoire » et la mission de 1995 (pp.70-75) et enfin vers la «Terra incognita» de Kalimantan, à laquelle il accéda en 1996 (pp. 76-79).

4 La troisième partie commence par le récit de la mission de 1998 (« De Gua Masri à Ilas Kenceng ", pp. 83-101) et la présentation des "Lascaux» de Bornéo. Puis, Luc-Henri Fage raconte la mission de 1999 ("Gua Tewet, l'apothéose d'un art rupestre ", pp. 102-115), celle de 2001, avec les anthropomorphes « de Gua Tamrin» (pp. 116-125) et de «Gua Ham, la mise en scène des mains négatives» (pp. 126-133), la mission de 2002 des «dames de Gua Jufri » (pp. 134-139), celle de 2003 et de «l'arbre à miel de Liang Karim » (pp. 140-145) et enfin la mission de 2006 avec le «fabuleux bestiaire de Gua Harto » (pp. 146-151).

5 Après cette chronologie précise des expéditions qui fait progresser le lecteur dans la temporalité des découvertes, toutes finement illustrées, c'est au tour de Jean-Michel Chazine de parler, de façon malheureusement un peu trop courte compte tenu de l'ampleur du volume, d'archéologie, avec «La naissance de Kalimantan dans la Préhistoire » (pp. 154-160) et d'art rupestre avec les fameux «Jeux de mains à Bornéo " (pp. 161-167). A noter tout particulièrement : la présence de mains féminines parmi les mains négatives, fournissant des "preuves formelles que les femmes [...] étaient également venues » dans les grottes.

6 Une courte conclusion, non signée, consacrée à des questions de protection et de conservation et intitulée "Le passé aura-t-il un avenir?", termine le corps de l'ouvrage.

7 On ne saurait trop souligner l'importance des découvertes faites à Bornéo - où pas moins de 38 grottes contenant des peintures rupestres ont été recensées - tant pour l'histoire du peuplement de l'Indonésie que pour leur dimension artistique. Avant les expéditions des deux auteurs de ce bel ouvrage, l'île de Bornéo, aussi grande que la France, était vierge de découvertes archéologiques. L'art rupestre de cette région a permis de remettre en cause la séparation matérialisée par ce qui a été appelée «la ligne de Wallace » qui établissait « une vraie frontière entre les mammifères de Bornéo et Sulawesi [Célèbes], c'est-à-dire entre l'Asie et les îles de la Sonde » (p.161). La découverte de ces grottes ornées révèle l'existence de liens au Quaternaire entre les habitants de part et d'autre du détroit de Macassar, autrement dit entre les peuples de l'Asie du Sud-Est et ceux de l'Australie.

8 Avec ses nombreuses illustrations couleur, ses chapitres faisant le récit chronologique des découvertes, et sa synthèse archéologique, ce livre d'une lecture aisée est à recommander à un public des plus larges qui pourra appréhender autant cette mémoire des grottes de Bornéo que les métiers de préhistorien et d'archéologue. 